\title{
How to Strengthen the Credibility of the Italian Pension Reform
}

\author{
Flavia Coda Moscarola ${ }^{\mathrm{a}}$ and Elsa Fornero ${ }^{\mathrm{b}}$ \\ ${ }^{a}$ Center for Research on Pensions and Welfare Policies (CeRP), Collegio Carlo Alberto, Moncalieri, Turin, \\ Italy. \\ E-mail: coda@cerp.unito.it \\ ${ }^{\mathrm{b}}$ University of Turin and Center for Research on Pensions and Welfare Policies (CeRP), Collegio Carlo \\ Alberto. \\ E-mail: elsa.fornero@unito.it
}

As a result of the reform process undertaken in the 1990s, the Italian pension system has replaced a generous but unsustainable Defined Benefit formula with a Notional Defined Contribution (NDC) formula and opened the path for voluntary-based second and third pillars. While the reform has put the system on a sustainable path, its most relevant side effects consist in the transfer of the pension risk to the individuals, who are then more exposed to the consequences of unfavourable economic cycles and to financial crises. The extremely slow phasing in of the reform, however, undermines its credibility and raises risks of it backfiring. We propose three measures to avoid this: (1) acceleration of the full adoption of the NDC formula, to achieve uniformity of treatment of genders, cohorts, and working categories, (2) elimination of incentives to early retirement and introduction of flexible retirement, and (3) promotion of financial literacy.

The Geneva Papers (2009) 34, 591-601. doi:10.1057/gpp.2009.24

Keywords: ageing; pension reforms; elderly work; retirement choices

\section{Introduction}

The year 1992 represents a turning point for the Italian pension system: before, pension reforms were of the free-spending type and rather generous in terms of benefits, recipients and eligibility requirements. Since then, sustainability reasons have forced restrictive reforms and cutbacks to reverse what appeared to be an everincreasing pension expenditure/GDP ratio.

These reforms profoundly changed pension design, particularly with the introduction (in 1995) of the Notional Defined Contribution (NDC) system. However, due to an excessively long transition, the phasing in of the reform will still be incomplete in 2050. This has created a double problem: on the one hand, specific measures had to be implemented in order to reduce expenditure in the short/medium term, and these "parametric changes" were not always consistent with the expected final steady state. On the other hand, the credibility of the reform has been undermined, as time progressively eroded the commitment towards its implementation, and political changes created the premises by which subsequent governments could revise measures undertaken by previous ones. This lack of consistency has increased workers' uncertainty and contributed to the impression of a stop-and-go process, with ambiguities as to the final configuration. The financial crisis has worsened the 
scenario: by reducing the attractiveness of pension funds and supporting the idea that the "best" pensions are provided by the state, the very concept of a multi-pillar pension system could be in jeopardy.

In our view, after almost 20 years since the first restructuring process, the Italian pension system's main problem is the lack of commitment with respect to completing the 1995 reform. However, a firm pledge towards a pension provision made up of a substantial public component of the NDC type and more robust supplementary pensions will (1) strengthen sustainability, without necessarily sacrificing adequacy, (2) promote uniformity of treatment between genders, cohorts, and working categories, without eliminating the solidarity in favour of less fortunate workers, and (3) increase flexibility in retirement age, by eliminating distortions in favour of early retirement.

In the next section, we present a few demographic and economic facts that have characterised Italy in the past two decades, so as to put the pension system and its reform into perspective; we then describe the main features of recently enacted reforms, provide an assessment of what has been achieved, particularly as far as the employment of older workers is concerned. As a conclusion, we argue that rather than looking for yet a new reform, Italy should take firmer steps towards the actuarial and diversified system introduced long ago and still to be applied.

\section{Unfavourable demographic and economic trends}

Together with Japan, Italy faces some of the fastest population ageing in the world. This trend is due to the combined effects of a general improvement in life expectancy and of idiosyncratic fertility changes. As in all other developed countries, life expectancy is steadily increasing. A forward shift of the maximum survival age is associated with the "rectangularisation" of the mortality profile by age - that is, the reduction in mortality rates for infants, the young and the middle aged. In the perspective of the pension system, this creates two consequences. First, more people reach retirement age - which is still comparatively low: 60.4 years vs. 61.5 of the average of the EU-15 countries. ${ }^{1}$ Second and foremost, it implies that individuals will enjoy their pension benefits longer. According to official statistics, ${ }^{2}$ a man born in 1940 and retiring at the age of 65 years had a residual life horizon of 17.5 years, which increases to 21.3 years for women. Life expectancy at retirement is expected to increase by about $0.2-0.3$ years for each subsequent cohort.

In addition to changes in mortality patterns, fertility rates have fallen sharply, as in most of the other Southern and Eastern European countries, with an average number of children per woman of 1.35 , well below the replacement level of 2.1 , although gradually recovering. As a result, the dependency ratio (the ratio between 65 years plus and 15-65 years), which was about 30 per cent as of 2000 , is expected to more than double by $2050 .^{3}$ The 60 years plus, which represented about 18 per cent of the

\footnotetext{
${ }^{1}$ Eurostat (2009b).

${ }^{2}$ Istat (2009).

${ }^{3}$ Eurostat (2009a).
} 


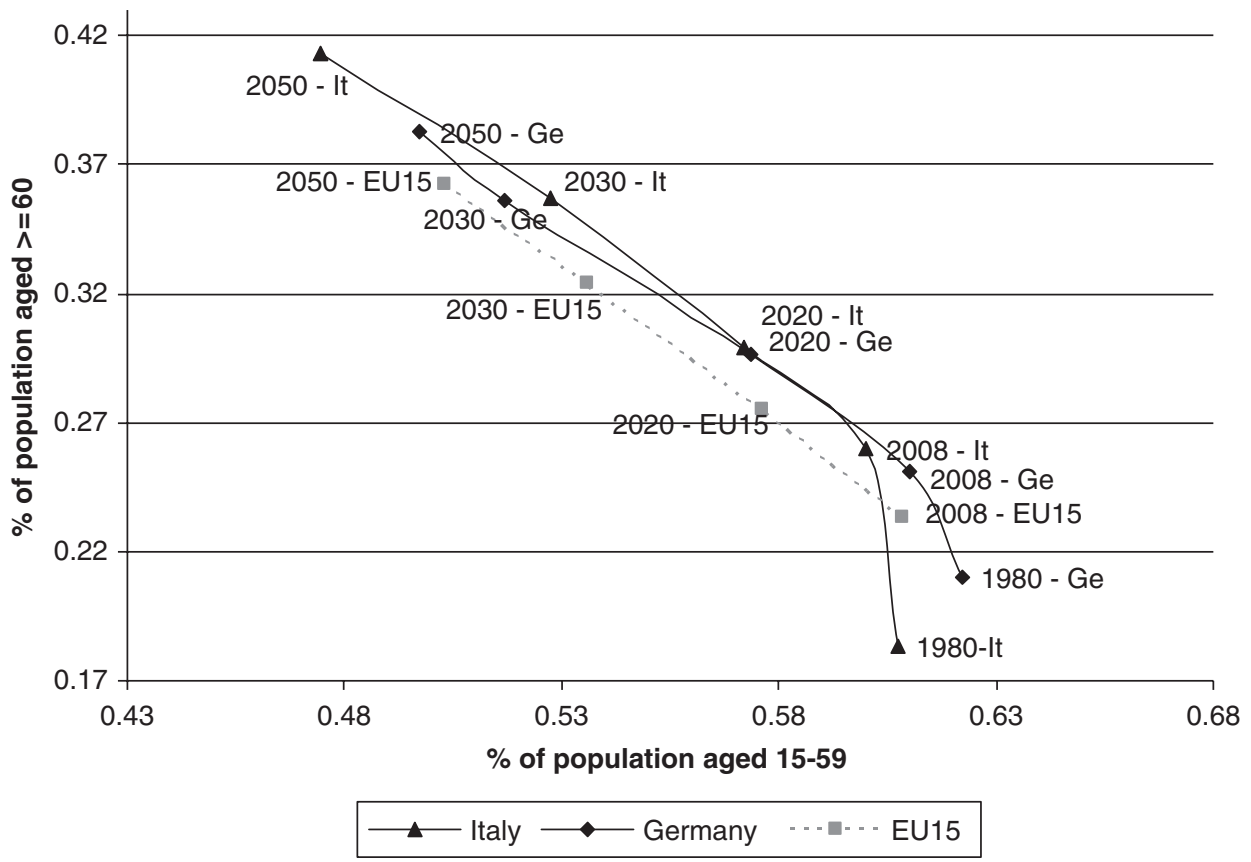

Figure 1. Population aged 60 years plus over population aged 15-59 years. Source: Our elaborations on Eurostat data (2009b).

population in the 1980s, are expected to reach 36 per cent in 2030 and 41 per cent in 2050; the 15-59 years, which represented about 60 per cent in 1980, will be 53 per cent in 2030 and 47 per cent in $2050 .{ }^{4}$ These demographic developments are reversing the traditional picture of Italy as a young country: until the 1980s, the share of the elderly population was lower in Italy than in many other European countries. In the following decades it increased very fast and, from 2020 on, it is expected to reach the highest level in Europe, surpassing for example Germany, now at the same level as Italy (see Figure 1).

To this rapidly changing demographic scenario, with negative consequences on the pension system, one should add a still low labour market participation rate, especially for women, a high youth unemployment rate and an overall weak economic performance, both in absolute values and in comparison with the achievements of other developed countries. The labour market participation rate of working age individuals is the lowest in EU-15. In the past five years (from 2004 to 2009), only 73 out of 100 individuals aged 25-29 years result to be employed against 83 out of 100 in EU-15. ${ }^{5}$ The young therefore delay their exit from their original family and their fertility decisions.

\footnotetext{
${ }^{4}$ Eurostat (2009b).

${ }^{5}$ Ibid.
} 


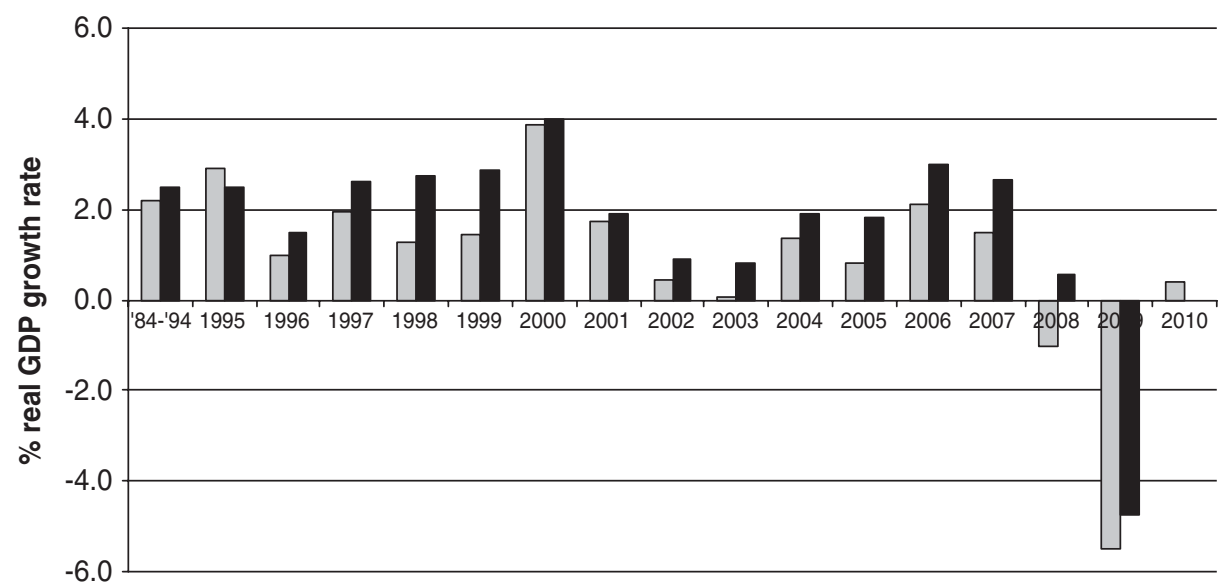

altaly $\square$ Euro area

Figure 2. Real GDP growth rates (percentage change from previous year). Source: Our elaborations on OECD Economic Outlook 85 database (2009).

As for the economic performance, in the period 1996-2008, the average GDP growth rate has been a modest 1.3 per cent per year, ${ }^{6}$ again lower than the European average. Indeed, in 6 of the last 13 years, the Italian real GDP growth rate (see Figure 2) has been around or under half the average rate of growth of the euro area countries. The present crisis exacerbates these structural problems: the expected rate of growth is actually deeply negative for 2009 , and only a very timid recovery, if at all, is expected in $2010 .^{7}$

This overall scenario has a relevant impact on the sustainability and adequacy of the Pay-as-you-go (PAYG), by far the largest component of the Italian pension system: with rapid ageing and sluggish productivity growth rates, the system is hardly in a position to promise generous pension benefits.

On the other hand, the prevalence of PAYG somewhat sheltered Italian households' pension wealth from the effects of the financial crisis, since very little wealth was accumulated in the crisis affected second and third pillars. However, the crisis itself is hardly increasing the popularity of pension funds, which the government tried to encourage as a supplement for the reduced public pensions. The confidence in the financial market has been shaken and this will discourage workers' participation.

\section{The reform process}

During the last two decades the Italian pension system has undergone two major reforms meant to re-design the system in the long run and a number of parametric changes directed at reducing short-term expenditure. Reforms were badly needed for

\footnotetext{
${ }^{6}$ OECD (2008).

${ }^{7}$ OECD (2009).
} 
sustainability reasons: the pre-reform system was unbalanced, highly fragmented, insufficiently transparent and plagued by significant distortions. The pension formula was of the Defined Benefit (DB) type, with benefits first determined by multiplying the "final wage" both by the number of years of work and by an accrual rate (normally 2 per cent) and then indexed to the growth rate of nominal wages.

The formula was "generous" on average, since benefits were not really (or not at all) correlated to contributions and to the expected longevity. Differences in pensionable earnings, in payroll tax rates, in the structure of survivors' benefits, in notional contributions for workers temporarily out of work, however, made redistribution not only pervasive but more than often "perverse" (i.e. from rich to poor). ${ }^{8}$ The 1992 reform, enacted in the aftermath of a financial crisis that brought the lira out of the European Economic and Monetary Union, represented the first cutback not only in pension promises, but also for existing pensions, which were awarded a less generous indexation mechanism, from wages to prices. It was however the 1995 reform that reshaped the system, by transplanting the actuarial equivalence principle into the PAYG method of financing and by selecting the nominal growth rate of GDP as the uniform rate of return on contributions (the NDC method). In the new system, eligibility requirements are based only on age (which marked a sharp differentiation from previous seniority pensions, awarded only on the basis of the years of contributions) and are flexible, in accordance with an actuarial correction of benefits by means of age varying annuity rates; these "transformation coefficients" were first set by the 1995 law as the opposite of the present value of a one unit benefit for the age group 57-65 years. However good these reforms were in establishing principles, both had to pay a political price to overcome opposition, in terms of a drastic delay in implementation. ${ }^{9}$

It was soon obvious that the transition was inadequate to cope with the need to restrain expenditure in the short run. Subsequent pieces of reform (in 1997, 2004 and again in 2008) sought then to reduce expenditure by tightening the eligibility requirements for seniority pensions. In so doing, however, the last two reforms interfered with the NDC scheme, in particular by establishing a differential retirement age for men and women - 60 years for women and 65 years for men - which in practice meant cancelling flexible retirement for men. ${ }^{10}$

The reforms also encouraged the creation of a funded pillar, to supplement future lower public pensions; however, after almost 15 years since the introduction of pension funds, both participation and contributions remain modest. ${ }^{11}$

${ }^{8}$ Distortions in favour of early retirement were particularly strong in seniority pensions, establishing eligibility after 35 years of contributions (15-20 in the public sector), without any actuarial correction of benefits.

${ }^{9}$ Paradoxically, Italy was the first country to introduce the NDC system, which Sweden adopted a year later. However, while Sweden envisaged a rapid application, in Italy the political compromise forced a very long transition, which created "protected" cohorts (those with at least 18 years of service by the end of 1995), pro rata cohorts (workers with less than 18 years of service), and "new" cohorts (those entering the labour market starting from 1996), which were entrusted to the new rules.

${ }^{10} \mathrm{On}$ the inter-generational and political implications of the Italian pension reform process and of population ageing, see also Brugiavini and Galasso (2004).

11 According to Covip (2008), about 26 per cent of entitled workers are enrolled and assets are only about 3 per cent of GDP. 


\section{An appraisal of the reforms' achievements}

How do these reforms fare in terms of reduction of the pension expenditure/GDP ratio? The slow phasing in of the reform translates into a very slow reduction of the ratio: starting at a level of 14 per cent in 2005, it will continue to rise over the next two decades, reaching a maximum of about 15.5 per cent in 2038 ; it will then start to decrease, converging to a level of about 14.3 per cent in 2050 and of 13.2 in $2060 .{ }^{12}$

One should stress that (despite an increasing absorption of resources in the shortmedium run, the so-called hump in the ratio) stabilising the level of pension expenditure over GDP in the course of the next 40 years will represent a remarkable result, given the sharp expected increase (from 30 per cent to about 60 per cent) in the old age dependency ratio. Other indicators - such as the standard Money's Worth Ratios, like the net present value ratio or the implicit rate of return - show that the reforms have indeed re-established long-term financial sustainability, ${ }^{13}$ a result that is primarily due to the application of the actuarial equivalence principle. ${ }^{14}$

Sustainability will, of course, be obtained by trading off the previous generosity of the first pillar: as reforms gradually phase in, first-pillar replacement rates (RRs), measured in gross terms, will decrease from about 65 to 73 per cent (depending on the working scheme) to values between 39 and 66 per cent for cohorts completely under the NDC system. In order not to put at risk the adequacy of their pension benefits, commonly (and roughly) evaluated by using a benchmark RR equal to 70-80 per cent, workers have been encouraged, mainly by means of tax advantages, to accumulate private pension wealth, to be converted into an annuity at retirement. Simulations show that a yearly contribution rate to the second pillar in the range of 7-8 per cent of gross earnings should be able to almost completely offset the reduction in first pillar benefits for private employees. ${ }^{15}$

The reforms will also greatly affect the redistribution generated by the pension system. By adopting an insurance principle as core device, the new NDC formula will cancel out almost all the redistributive features of the first pillar, both the "perverse" (mainly due to the effect of taking the final earnings as the base to calculate the benefit) and the "good" ones (due to the presence of floors and ceilings in payroll taxes and benefits levels). The position of low income workers will only partially be safeguarded by the reform through the provision of a means-tested old age allowance. The dispersion across permanent income levels of the internal rate of return granted by the system will disappear and the role played by the pension system in reducing income concentration, although already small in the pre-reform period (i.e. implying on aggregate an almost null redistribution), will further decrease.

12 Ragioneria Generale dello Stato (2008).

${ }^{13}$ Fornero and Castellino (2001); Borella and Coda Moscarola (2006 and 2009).

${ }^{14}$ One must not forget that the (Italian version) of the NDC system is not waterproof and that flaws in the application of the actuarial mechanisms - such as the rather slow revision of the transformation coefficients (every 3 years) - are still expected to create financial imbalances between contributions and expenditure, which the government will have to cover.

15 This corresponds roughly to the amount of the annual flow (6.9 per cent) to the severance pay fund, which has indeed been targeted as the main source of financing for the pension funds. 
The distributive effects of the second pillar will also be rather small, since both systems will be based essentially on the same actuarial formula, although differential portfolio choices by income classes could produce differential returns. While financial sustainability is restored, adequacy of provisions for the young and future generations could be a problem. Although provided with a better regulated and better diversified pension system, the young generations are nevertheless at risk of inadequate pension wealth accumulation, as the performance of the labour market has been rather weak and the accumulation of discretionary savings in pension funds or other saving instruments is hampered by a more uncertain and discontinuous earning profile. ${ }^{16}$

\section{Adding a "fourth pillar": Labour income in retirement}

Increasing retirement age is, of course, both the natural response to increasing longevity and one of the most effective countermeasures to preserve the adequacy of pension benefits. It is also an essential feature of the NDC system, which does not need a "normal" retirement age to work, a flexible age group being consistent with the operation of an actuarially neutral formula. European countries have been pressed to implement policies for active ageing, encompassing measures such as promoting lifelong learning and flexible working arrangements to enable older workers to remain and participate actively in working life and emphasising the "age dimension" of human resource management. ${ }^{17}$

In Italy, pension reforms have repeatedly dealt with the issue, more often implementing a compulsory increase in the age of retirement or in the age/seniority requirements. In the Italian system, the mandatory retirement age for old age pensions is 65 years for men and 60 years for women. ${ }^{18}$ Workers are, however, entitled to continue to work in the same workplace after they have met the requirements for old age pensions, conditional on the employer's assent and only up to the age of 67 years if public employees (70 years for university professors, judges and other "privileged" categories). The full possibility to cumulate pension and earnings has only been recently introduced: retirees are thus allowed to take on a new job without incurring a reduction of their pension benefit (a few limitations are still in place for NDC workers who do not meet specific age/seniority requirements).

The law has been considered as radically changed with respect to the past. The long-standing opposition, particularly from trade unions, to cumulating pensions with earnings can be accounted for by the lump of labour fallacy, that is, the idea that keeping the elderly in the labour force means a reduction of job opportunities for the young. What can be the consequence, in the short run, of labour market rigidities is instead attributed to the natural substitution of the elderly by the young in a market that can only allow for a fixed number of jobs. In practice, more than increasing the chances of the young, the effect was to encourage relatively young pensioners to join

\footnotetext{
${ }^{16}$ Fornero (2008).

17 Arrowsmith and Hall (2000).

${ }^{18}$ A differentiation that has brought the European Court of Justice to condemn Italy for gender discrimination, in this case against men (see Section 6).
} 
the black market (still a pathology of the Italian economy). However, the adoption of the contribution based formula to determine pension benefits has weakened the argument: if the pension benefit is actuarially equivalent, then a minimum age has to be legislated (the inferior end of the age group for the variation of actuarial coefficients) but a formal prohibition to cumulating pensions with earnings has little or no justification at all.

In any case, as a consequence of various normative interventions and following a general European trend, the participation of older workers in Italy is steadily increasing: it rose by 5 percentage points between 1996 and 2006. However, participation rates of older workers are still very low; from 2008 on, only 34.4 per cent of individuals aged 55-64 years still work, compared to the 47.4 per cent of the average EU-15. ${ }^{19}$ Pension reforms will certainly accelerate the process. On the one hand, the minimum retirement age is increasing and the seniority requirement to access seniority pensions is becoming more stringent. In particular, the gap between the minimum early retirement age and the old age pension requirement is narrowing. ${ }^{20}$ On the other hand, as the NDC rule is phased in, the financial incentives to retire early, embedded in the DB formula, will be cancelled out; adequacy concerns will induce workers to postpone retirement, while actuarial neutrality will not penalise them any longer for doing so. In conformity to life cycle modelling, empirical evidence shows that individuals react to financial incentives generated by the pension formula. $^{21}$

The implementation of active reforms of the labour market devoted to increasing labour market participation of the elderly cannot, however, disregard the demand side, which calls for a careful evaluation of both the age productivity profile and the economic advantages of employing older workers. Productivity is likely to decrease with age, ${ }^{22}$ but in Italy automatic mechanisms of career progression preclude a reduction in the wage of employed workers. Rigidities in the labour market make it less convenient to hire older workers or make them the most likely to be fired in case of a crisis (of course, with great variations among sectors). In addition, the opportunity of employing older workers depends on the availability of care services for children and the elderly. As long as the public supply of such services is underdeveloped, lengthening the active life of workers, especially women, will induce an undesirable lack of assistance towards these categories in need.

19 Eurostat (2009b).

${ }^{20}$ The project of introducing gradual retirement schemes, used more so in Northern European countries, with the purpose of discouraging early retirement and/or recourse to disability pensions, was abandoned after a few unsuccessful attempts.

${ }^{21}$ For example, see Coile and Gruber (2000), Gruber and Wise (2004) for the United States, Baker et al. (2003) for Canada, and Belloni and Alessie (2009) for Italy.

22 The literature on the topic focuses on particular sectors and the results are mixed. Analysing the sector of car manufacturers, for example, Börsch-Supan and Weiss (2007) find that the age productivity profile is fairly stable; it is, however, the job tenure that keeps older workers' productivity from falling. In particular, while older workers are slightly more likely to make errors, they hardly ever make any severe errors. 


\section{A still unstable outlook}

In a scenario where the government (notwithstanding recurrent warnings by international organisations, like the OECD, on the still very high Italian pension expenditure/GDP ratio) showed reluctance to engage in yet another pension reform, in November 2008 the European Court of Justice condemned Italy for gender discrimination on the basis of a legislated difference in retirement ages (65 years for men and 60 for women). ${ }^{23}$ The court sentenced that the difference in retirement ages is at odds with the EU principle of equal treatment and that it cannot be justified - as argued by the Italian government - in terms of an ex post compensation for women's lower opportunities in the labour market. The issue reveals an inconsistency between long- and short-term political objectives: while it can make sense, in the short-term, to "compensate" with a lower retirement age the cohorts of women approaching retirement, who suffered from many discriminations in the labour market (such as lower earnings, more frequent work interruptions, not to mention the "double burden" of working at home and in the job place), the same logic is self-defeating in the long term. It risks perpetuating and widening exactly the disparities for which today's compensations are considered socially reasonable. Empirical evidence, for example, suggests that having access to early retirement reduces the incentives to invest in human capital, particularly in terms of on the job training. ${ }^{24}$ This points to the labour market as the main place to tackle the disparities, and to family policies and care services as means to encourage women's participation. While there seems to be no real problem of human capital accumulation in Italy - the country records a higher number of female than male university graduates - women still lack equal chances of success in the labour market, mainly because they are not backed up by care help (kindergartens, formal care for the elderly, etc.).

As for the Italian government's response to the European sentence, it would make little sense, in the NDC world, to force both men and women to retire at the age of 65 years, because it would mean loosing one of its best features, that is flexibility of retirement. Instead, it seems more sensible to fully endorse, for both genders, the NDC system, by restoring (for men) and updating the age group of flexible retirement. Considering an increase of the minimum retirement age of a couple of years for women (from 60 years to 62 years) and a reduction of 3 years for men (from 65 years to 62 years), the age group could become $62-67$ years, with benefits varying according to the actuarially neutral coefficients officially updated in 2007 and starting immediately for all workers on a pro rata mechanism, regardless of the number of years that separate them from retirement.

Apart from the sentence, another threat/opportunity comes from the financial crisis, which although not bearing a direct impact on the pension system can nevertheless affect its future evolution and, more specifically, the political sustainability of the system.

\footnotetext{
${ }^{23}$ Although the 5 years difference is stipulated for all workers, both private and public, the Court's judgement only applies to the public sector.

${ }^{24}$ Jacobs (2009).
} 
600

Indeed, the adoption of a multi-pillar system, partially PAYG and partially funded, has been motivated by a risk diversification strategy: the GDP growth rate is typically lower but more stable than the (average) financial return and the two are not (or only weakly) correlated, allowing for a mutual hedging of bad performances. In this particular case, however, the economic crisis was induced by financial markets and it is hardly plausible that the hedging mechanism will be effective. The crisis thus calls into question the "pension portfolio diversification" at the root of the mixed system.

The crisis has also created opportunities. In particular, it has revealed the need for more careful supervision, higher transparency and greater competition in the markets, and put in broad daylight the need for financial education programmes meant to enable individuals to better plan their retirement savings. ${ }^{25}$

In conclusion, the transition undergone by the Italian pension system, already marked by intermittent parametric changes meant to more vigorously address an increasing pension expenditure/GDP ratio, has recently been unsettled by two external shocks (the sentence by the European Court of Justice and the financial crisis), which will force the government to step in. There are signs that could weaken the commitment towards implementing the NDC system, introduced (but never applied) almost 15 years ago. In our view this inconsistency risks taking the pension system back to the old path of financial unbalances, bad redistribution and pervasive distortions.

\section{References}

Arrowsmith, J., Hall, M. (2000) Industrial relations and the ageing workforce: A review of measures to combat age discrimination in employment, European Industrial Observatory On-line (EIRO).

Baker, M., Gruber, J. and Milligan, K. (2003) 'The retirement incentive effects of Canada's income security programs', Canadian Journal of Economics 36(2): 261-290.

Belloni, M. and Alessie, R. (2009) 'The importance of financial incentives on retirement choices: New evidence for Italy', Labour Economics 16(5): 578-588.

Borella, M. and Coda Moscarola, F. (2006) 'Distributive properties of pension systems: A simulation of the Italian transition from defined benefits to notional defined contributions', Giornale degli Economisti e Annali di Economia 65(1): 95-126.

Borella, M. and Coda Moscarola, F. (2009) Microsimulation of pension reforms: Behavioural versus non behavioural approach, working paper no. 86/09, CeRP.

Börsch-Supan, A. and Weiss, M. (2007) Productivity and the age composition of work teams: Evidence from the Assembly Line, working paper no. 148/2007, MEA.

Brugiavini, A. and Galasso, V. (2004) 'The social security reform process in Italy: Where do we stand?' Journal of Pension Economics and Finance 3(2): 165-195.

Coile, C. and Gruber, J. (2000) Social security and retirement, working paper no. 7830, NBER.

Covip (2008) Relazione per l'Anno 2007, Rome.

Eurostat (2009a) 2009 ageing report: Economic and budgetary projections for the EU-27 member states (2008-2060), European Economy 2/2009, provisional version working paper, Brussels.

Eurostat (2009b) 'Online Statistical Database', from //epp.eurostat.ec.europa.eu/.

Fornero, E. (2008) 'Aiutare i giovani a costruirsi una pensione e gli anziani a utilizzare meglio le loro risorse', AREL Europa Lavoro Economia, Special Issue, October.

Fornero, E. and Castellino, O. (eds.) (2001) La riforma del sistema previdenziale italiano, Bologna: Il Mulino.

\footnotetext{
${ }^{25}$ Lusardi and Mitchell (2007).
} 
Gruber, J. and Wise, D. (2004) Social security programs and retirements around the world, working paper, NBER, University of Chicago, Chicago.

Istat (2009) 'Speranza di vita alla nascita e a 65 anni, per sesso e regione - Anni 2005-2008', from www.demo.istat.it.

Jacobs, B. (2009) Human Capital, Retirement and Pension Saving, paper prepared for ESF Forward Look final conference "Ageing, Health and Pensions in Europe", the Hague (April 22).

Lusardi, A. and Mitchell, O.S. (2007) 'Financial literacy and retirement preparedness: Evidence and implications for financial education', Business Economics 42: 35-44.

OECD (2008) OECD Economic Outlook, 84 (November).

OECD (2009) World Economic Outlook, Update (28 January).

Ragioneria Generale dello Stato (2008) Mid-long term trends for the pension, health and long term care systems, projections of the Department of General Accounts updated to 2008, Rome.

\begin{abstract}
About the Authors
Elsa Fornero is a professor of Economics at the University of Turin and Scientific Coordinator of Center for Research on Pensions and Welfare Systems (CeRP, Turin, http://cerp.unito.it). She is a member of the Government Commission at the Ministry of Welfare for the evaluation of pension expenditure and has been an independent pension expert for the World Bank. She has written extensively on households savings and pensions (http://web.econ.unito.it/fornero/).

Flavia Coda Moscarola holds a PhD in Economics from the University of Turin; she is Senior Researcher at CeRP. Her research fields are Microsimulation, Social Security and Aging. She has worked extensively on the analysis of the distributive effects of pension reforms, on long-term care, as well as on the impact of migration policies on public budget.
\end{abstract}

